\title{
Developing Related Cultural Awareness in TEFL
}

\author{
Haiyan Gu \\ Xi'an International University, Xi'an Shaanxi, 710077, China
}

Keywords: Cultural Awareness, Target Language.

\begin{abstract}
Broadly speaking, the chief aim of teaching English as a foreign language (TEFL) is to enable learners to communicate successfully with native speakers. It is commonly thought that language is a tool for communication. Is mastery of the "tool" equal to success in intercultural communication? Do people with different mother tongues think and behave alike? What factors affect learners' appropriateness in intercultural communication? This paper is meant to probe into the relationship between the attainment of native like competence and related cultural awareness. It claims that only mastery of linguistic competence is not enough for successful communication. It is quite necessary to develop a full understanding of the systems of knowledge, belief, customs, morals and emotions of the new culture as well as the social and psychological integration of the learner with the target language.
\end{abstract}

The paper consists of three parts. The introduction carries an argument that language teaching cannot be separated from culture in which language is deeply embedded. The second part lists several major reasons to develop learners' related cultural awareness. The final part offers some suggestions and methods to develop an intercultural perspective and overcome learner' cultural barriers in communication with native speakers.

\section{Introduction}

It is commonly thought that language is a tool for communication and a good command of the "tool" is equal to success in intercultural communication. It is in this misconception that English teachers in China have been concerned merely with developing, learners' linguistic competence. Accordingly, traditional teaching methods such as Grammar Translation Method, the Direct Method are used, which focus on mastery of language. But those methods turn out to be quite disappointing. Learners trained by those methods, more often than not, are unable to communicate with native speakers.

Rather desperate, English teachers turn to contemporary teaching methodologies. Meanwhile they come to realize the important fact that English is not only a different language, but also an alien culture. Successful communication depends on both command of the target language and on mastery of the target culture. So in language teaching, the incorporation of related culture into language lessons is rather necessary. The national inspectors of education in Britain stated clearly that the aim of teaching a foreign language is "to help learners to increase social competence", "to foster positive attitudes towards other countries and peoples", "to awaken an interest in foreign cultures and lifestyles" (Harrison, 1991). For the first time, to raise cultural awareness in TEFL is taken into consideration.

\section{The Major Reasons for Developing Related Cultural Awareness}

Language learning cannot be separated from culture in which language is deeply embedded. Teaching a language is a lot more than developing learners' linguistic competence. It also implies developing related cultural awareness and a full understanding of the systems of belief, customs, morals and emotions of the target culture, language teaching in conjunction with related culture are 
mainly justified from the following perspectives:

\section{Definitions of Culture and Its Close Relationship with Language}

Culture is a technical term in anthropology which is now widely used in philosophy, psychology, psychiatry, sociology, economics and biology etc. The word derives from Latin "cultura"(from the verb "colere") with the meaning of "tillage of the earth." The Oxford Dictionary first carried the word in 1420 which meant "husbandry". In the 16th century, it was used to convey "training of manners or their mind."

Culture has been defined from different perspectives. Hundreds of definitions have been put forth. The English anthropologist Tylor defined: "culture...is that complex whole which includes knowledge, belief, art, law, morals, custom, and any other capabilities and habits acquired by man as a member of society." (Encyclopedia) Kluckhohn and Kelly defined it as "all those historically created designs for living explicit and implicit, rational, irrational and non-rational, which exist at any given time as potential guides for the behavior of man." (Lado, 1957).Nida agreed to the definition that culture is "the totality of practices of a society"(Nida, 1993).Now the commonly accepted view is that culture is the common knowledge and values that people of a particular group share.

Then what is the relationship between language and culture? John Fornas asserted that "culture is symbolic communication" (Fornas, 1995). Culture is everywhere in human life and society: some of the flows of culture are clearly observable, others temporary.

Language is a system of arbitrary vocal symbols by means of which the members of a speech community communicate, interact and transmit their culture. Symbols make it possible to describe what is visible, what is hidden; what is present, what is in the past. Through language, any knowledge, ideas, beliefs, values and experiences are conveyed vividly and explicitly. It is through webs of symbol that we enjoy culture. On the other hand, culture makes constant impact on language, for example, Buddhism in China has resulted in lots of coinages such as "sēng" (Buddhist monk), "nīgü"(Buddhist nun), "Pǘsá" (Buddha ), sēngyùan (Buddhist temple ), "hóngchén" (human society ), "yánwang" ( King of Hell ), "dìyù" (Hell), ect. Christianity has contributed to such coinages as "minister, monk, bishop, priest, mass, church, bless, cross, Easter" ect. Therefore language and culture are closely related to each other. The former expresses and transmits the latter and the latter includes and enriches the former. Judging from the close relationship, Joyce Valdes concludes that "There is no way to avoid teaching culture when teaching a language" (Harrison, 1991) though the teacher is not fully conscious of that.

\section{Culture Related-Schemas and Acculturation}

Acculturation is the process of adapting to the target culture. According to Schumann (1978), successful language learning is more likely when learners integrate themselves with the target language group psychologically and socially. When it comes to the social and psychological integration, It has something to do with culture-related schemas which means "the coherent configuration of behaviors, customs, institutions and values that characterize culture or civilization." (Encyclopedia. 1988: 385). Once formed, the existing schemas exert great influences on the way we organize, interpret and retain the meaningful information. An American child grown up in America thinks, speaks, interprets and behaves in American way and a Chinese in a Chinese way. On cultural thought patterns Kaplan pointed out that "different cultures have different rhetorical forms and styles resulting from their particular approaches to thought." (Harrison, 1991).Great differences exist between Chinese and Westerners in writing essays. Westerners encourage contents before forms and priority is given to originality and creativity while Chinese emphasize forms which are learnt through various model compositions. Quotations from the authorities, idioms and old-sayings are marked with flying colors. That's why the same English paper is usually scored differently if graded by Western and Chinese teachers respectively. The essay marked "Excellent" by a Chinese teacher may be flunked by a Western teacher and vice versa. The different rhetoric patterns and grading criteria reflect the different culture-related schemas. This is because the Westerners are greatly influenced by 
Aristotle and Plato while Chinese by Confucius. Kaplan also reminds us that the Easterners who go to Western countries to study are sure to undergo culture shock. The teacher's explanations of the differences can certainly lesson misunderstanding and enhance acculturation.

\section{Cultural Barriers and Communication Conflict}

The Latin word "communicatio" means sharing something with others. In human interactions, communication aims at mutual understanding on the basis of shared customs, beliefs, values and ideas etc. Culture is the subject matter of communication and is communication natural and necessary process for conveying culture.

Both culture and communication are context sensitive. Proper speech in this context may not be proper in another especially in intercultural communication. This is because different languages enshrine different values, beliefs, customs. What is acceptable in this country may be totally unacceptable in another, for example, "Where are you going?" is a common way of greeting in China but may make English native speakers quite angry. They feel as if they were regarded as "apies”. To address somebody by the last name alone is term of endearment in China but may sound rather offensive to Westerners. The overuse of expressing "thanks" is considered rather polite behaviors by Chinese but may make English native speakers quite uncomfortable.

What is more, culture defines social situations differently. What works in one country may not work in anther. In China it is improper to open the gift immediately in the presence of the gift-sender while in America it is a way of expressing appreciation of the gift in time. When invited to dinner at a Chinese home, it is polite to leave a little on the dinner table while at a Westerner's home it is more agreeable if the guests finish all the dishes. In telephone conversation, a Chinese usually won't identify himself unless asked to do so. In English speaking countries, it is normal for the caller to identify himself first to show politeness. Ignorance of the cultural differences may cause communication conflict or pragmatic failure. To some degree, cultural differences are responsible for a great deal of confusion and even hostility when people come into contact. So for successful communication, shared knowledge of the target language and the target culture is essential. Awareness of the various perspectives if the target culture o a deep level can certainly lessen misinterpretations and avoid communication conflict.

\section{Ways of Incorporating Related Culture into the Target Language Lessons}

According to Kramsch (1993), the teaching and learning of cultural knowledge is often ignored because it is challenging and requires a bit more thought and creativity. The following methods may contribute to developing related cultural awareness in TEFL in China.

(1) A much culture-oriented English syllabus must be adopted. This implies a shift away from the existing language-focus, thematically based program. The old syllabus entails two disadvantages. First, learners cannot communicate successfully with native speakers because communication is not learnt through communication. Second, they do not gain any insight into English way of life since they are not familiar with their culture. For effective language teaching, a more scientific syllabus focusing learners on both target language and related culture must be used.

(2) A set of new textbooks incorporating related culture into the teaching materials must be compiled in a notional-functional approach which makes language learning more meaningful and effective. Meanwhile the use of supplementary authentic materials can broaden learners' horizon when they con into contact with more culture diversities.

(3) Effective language teaching places a high demand on the teacher. He is supposed to be good at L1, L2 and cultures concerned so that he can conduct a contrastive analysis and find out the similarities and differences between the two languages. It goes without saying that it is much more difficult to teach a combination of the target language and the target culture than to teach the mechanics of the target language alone because culture permeates everywhere and it covers more than it reveals.

(4) Language learners' self-development of cultural awareness is also very important. Being 
limited in learning hours in class, they are encouraged to be responsible for increasing their communicative competence. Although few people are lucky enough to go abroad, they are not totally detached from contact with English speakers. They are to listen to VOA, BBC, watch a lot of English films, read literary works, English with native speakers who teach in China. Only in this way can they have further understanding of the related customs, beliefs, attitudes, traditions, etiquettes, lifestyles, ways of behaviors and thinking which are characteristic of the native speakers.

(5) The teacher sees to it that in teaching listening, speaking, reading, writing and translating, he is supposed to clarify the key target language points and ads related cultural interpretations if necessary. Explanations of the cultural differences between Chinese and English can contribute to overcoming cultural barriers to full comprehension and appreciation of the texts . what is more, attention to related cultural details doubles the usefulness of the lesson, and brings livelihood to the classroom.

\section{Conclusion}

In order to achieve native-like most teachers agree that it is important and reasonable to develop cultural awareness in TEFL. The methods listed above can certainly contribute to raising cultural awareness. But how to make learners internalize cultural patterns within the shortest possible time is a difficult job and it is still a problem worthy of further attention and study in China.

\section{References}

[1] Deng Yanchang, Liu Runqing. Language and Culture. Peking: Foreign Language Teaching and Research Press, 1989.

[2] Fornas J. Cultural Theory and Late Modernity. Sage Publications Indies Pvt Ltd,1995.

[3] Harrison B. Culture and the Language Classroom. Macmillan Publishers Ltd, 1991.

[4] Hu Wenzhong. Culture and Communication. Peking: Foreign Language Teaching and Research Press, 1994.

[5] Kramsch C. Context and Culture in Language Teaching. Oxford: Oxford University Press, 1993.

[6] Lado R. Linguistics across Cultures. The University of Michigan. 2nd edition,1995.

[7] Liu Qing, Zhou Rong. Cultural Differences and Foreign Language Teaching. Theory and Practice of English Teaching. Peking: College English Press, 1995.

[8] Nida E A. Language, Culture and Translating. Shanghai: Shanghai Foreign Language Education Press, 1993.

[9] Park Myng-Seok. Communication Styles in Two Different Cultures. Korean and American, Hanshain Publishing Co. 2nd edition, 1994.

[10] Pütz M. Language Contact and Language Conflict. University of Duisburg Press, 1994.

[11] Schumann J H. The Pidginization Hypothesis: A Model for Second Language Acquisition. Newbury House, 1978. 